\title{
Primary and secondary effects of social origins on educational attainment: New findings for England
}

\author{
Erzsébet Bukodi $^{1}$ (D) | John H. Goldthorpe ${ }^{2}$ (D) | Yizhang Zhao ${ }^{3}$
}

${ }^{1}$ Department of Social Policy and Intervention, Nuffield College, University of Oxford, Oxford, UK

${ }^{2}$ Nuffield College, University of Oxford, Oxford, UK

${ }^{3}$ Tsinghua University, Beijing, China

\section{Correspondence}

Erzsébet Bukodi, Department of Social Policy and Intervention, Nuffield College, University of Oxford, Oxford, UK.

Email: Erzsebet.bukodi@nuffield.ox.ac.uk

\section{Funding information}

This work was supported by British Academy [Grant Number MD\170031]

\begin{abstract}
We aim to bring together two current strands of research into inequalities in individuals' educational attainment that are associated with their social origins: that concerned with the "primary" and "secondary" effects of social origins in creating inequalities, and that concerned with the relation between these inequalities and different components of social origins, taken to represent different forms of parental resources. Our main findings are the following. The secondary effects of social origins-their effects via the educational choices that young people make given their prior academic performance-are clearly operative across five key educational transitions within the English educational system. More specifically, we estimate that $35 \%$ of the total effect of social origins is secondary in the earliest transition that we consider, and from $15 \%$ to $20 \%$ in the subsequent four. Furthermore, mediation analyses reveal that secondary effects are most strongly associated with parental education and then, to a lesser degree with parental status, while little association exists with parental class and none at all with parental income. Primary effects are also at all transitions most strongly associated with parental education and status but in this case both parental class and parental income do retain some importance. We suggest an explanation for our empirical findings as resulting largely from the concern of highly educated, professional parents, and their children to
\end{abstract}

This is an open access article under the terms of the Creative Commons Attribution License, which permits use, distribution and reproduction in any medium, provided the original work is properly cited.

(c) 2021 The Authors. The British Journal of Sociology published by John Wiley \& Sons Ltd on behalf of London School of Economics and Political Science 
avoid the occurrence of downward intergenerational mobility, especially in terms of education and status.

\section{KEYWORDS}

education, social mobility, social origins

\section{1 | INTRODUCTION}

This paper brings together two current strands of research into inequalities in individuals' educational attainment that are associated with their social origins: that concerned with the "primary" and "secondary" effects of social origins in creating inequalities, and that concerned with the relation between these inequalities and different components of social origins, taken to represent different forms of parental resources.

The primary effects of social origins in regard to educational inequalities are those that lead to differences in young people's academic performance; the secondary effects are those that lead to differences in the educational choices that young people make, given performance. The distinction is of long standing, being initially suggested, if only implicitly, by Boalt (1947) then, more explicitly, by Girard and Bastide (1963), and finally spelled out as now generally understood by Boudon (1974). For a time, relevant research was held back by difficulties involved in making the conceptual distinction operational in a fully satisfactory way; but these difficulties were progressively overcome and an effective methodology developed and deployed (Erikson et al., 2005; Erikson \& Jonsson, 1996; Jackson et al., 2007; Kartsonaki et al., 2013). Studies comparing the part played by the primary and secondary effects of social origins in creating educational inequalities have by now been carried out across a range of advanced societies (see e.g., Jackson, 2013a). The main results that have been produced, relating to educational careers made largely in the later 20th century, may be summarized as follows:

1. In all educational transitions in all modern societies secondary as well as primary effects are involved in educational inequalities. Young people of more advantaged social origins tend to make more ambitious educational choices than do young people of less advantaged origins who have similar levels of previous academic performance (Jackson, 2013b).

2. The relative importance of secondary effects is influenced by the extent to which educational systems are stratified and selective: that is, by the extent to which secondary and tertiary institutions are hierarchically ordered and access to them is based on performance rather than on student and parental choice. But while stratification and selectivity are associated, the former tends to increase the secondary effects but the latter to reduce them, thus making their relative importance in any particular educational system difficult to predict (Jackson \& Jonsson, 2013, pp. 312-313). Thus, for example, in Germany both stratification and selectivity are relatively strong and in England relatively weak, but the importance of secondary effects does not seem to be systematically different. ${ }^{1}$

3. Some general, though not entirely consistent, cross-national tendency exists (Jackson, 2013a) for secondary effects to weaken across successive educational transitions. This would appear to result from selectivity based on previous performance usually becoming stronger at higher educational levels, with the scope for choice being thus reduced.

4. There is some evidence that secondary effects are becoming relatively less important over time, but this is strongest for countries such as Sweden (Erikson \& Rudolphi, 2010; Rudolphi, 2013), where sustained efforts have been made to provide students with relevant information and support in regard to the educational choices available to them and to reduce the costs associated with more ambitious choices. 
Research into the effects of different components of social origins on individuals' educational attainment is of more recent origin. Dissatisfaction became apparent over supposing that, in treating social origins, variables such as parental class, status, and education could be used indifferently, on the assumption that these were "interchangeable indicators" in the sense of Lazarsfeld (1939). And there was in turn a growing awareness that where only one such indicator was used, effects of other parental attributes would to some extent be "picked up" in what could be a misleading way (e.g., Jaeger, 2007).

Bukodi and Goldthorpe (2013) proposed (and see also Buis, 2013; Erikson, 2016; Erola et al., 2016) that in the analysis of educational inequalities social origins should be explicitly "decomposed," and seen as capturing different forms and levels of family resources. Thus, parental class could be taken as an indicator of economic resources, given its association not only with current income level but, more importantly, with income security, short-term income stability, and longer-term income prospects (Bukodi \& Goldthorpe, 2019; Chan \& Goldthorpe, 2007; Goldthorpe \& McKnight, 2006). Parental status could serve as an indicator of sociocultural resources, given its association with levels and patterns of cultural consumption and other forms of social participation (Chan, 2010; Chan \& Goldthorpe, 2007). And, parental education could then be seen as indicating specifically educational resources in the sense of parents' capacity to further their children's educational careers through creating a supportive home learning environment and providing them with informed guidance through the educational system (Pfeffer, 2008; Schütz et al., 2005).

The main results emerging from this body of previous research are the following:

1. While, as would be expected, parental class, status, and education are positively correlated, the correlations are for most part only moderate, and when all three are introduced together as variables in regression analyses of children's educational attainment, problems of multicollinearity rarely arise.

2. Parental class, status, and education all prove to have independent and to a degree cumulative effects on children's educational attainment. Neglecting any one does, therefore, lead to an underestimation of the overall effect of social origins. As regards their relative importance, some variation occurs by educational transition but the effect of parental education turns out to be in in general stronger than that of either parental class or status.

3. As regards changes over time, there is again variation by transition but, in England at least, the effect of parental education, and possibly also that of parental status, appear to be strengthening while that of parental class weakens. That is to say, there are indications that parents' educational and perhaps also more general sociocultural resources are becoming more consequential for their children's educational attainment than their economic resources.

In seeking to bring these two strands of research together, we focus on secondary effects in educational inequalities and their importance relative to primary effects while at the same time examining how far primary and secondary effects differ in their association with parental class, status, and education. And we are now able to include parents' current income directly in our analyses, as a further indicator of parental economic resources in addition to class. In the earlier studies of primary and secondary effects referred to, individuals' social origins have been mainly treated in terms of parental class or of parental education. Comparisons have then been made (see, e.g., Jackson, 2013c) of the results thus obtained, though with no consistent differences emerging. However, we aim to make a distinctive contribution in including parental class and education and also parental status and income simultaneously in our analyses. We also cover a more comprehensive range of educational transitions than in most previous research.

Finally, we should note that our paper is motivated in one other way. That is, by the position recently taken up by a number of economists who claim-with no reference to the contrary findings of sociologists-that within the English educational system secondary effects have by now more or less disappeared. Key educational transitions, and in particular that to higher education, are overwhelmingly determined by individuals' prior academic performance. And, the policy implication is then stressed that attempts at reducing educational inequalities should 
be concentrated on levelling up performance-that is, on reducing primary effects (Crawford et al., 2017, ch. 5). The main empirical support for this position comes in a paper by Chowdry et al. (2013). On the basis of analyses of administrative data, it is concluded that while there are marked differences in rates of entry into higher education by "socio-economic background," these are essentially accounted for by differences in prior examination results rather than by students of disadvantaged origins declining the possibility of going on to higher education where this possibility exists. It has, however, to be noted that, as Chowdry et al. indeed recognize (2013, p. 439), the data they have to use in determining social origins are "weak." No information is available on parents' class, status, education, or income-only on a number of characteristics of the neighborhoods in which they live and on whether or not their children were eligible for free school meals. This information is combined, through a principal components analysis, to produce a "socio-economic status index," and students are then grouped into more or less advantaged background quintiles. It is claimed that this procedure is validated by a cross-tabulation with similarly constructed quintiles using individual-level data from survey-based research, the Longitudinal Study of Young People in England-the survey that we use in this paper. But the results presented are scarcely compelling. ${ }^{2}$

In the light of the foregoing, the two research questions on which we focus are the following:

1. In England, do secondary effects of social origins still operate, in addition to primary effects, in creating disparities in the transitions that young people do or do not make in their educational careers; and, insofar as they do operate, what is their importance relative to that of primary effects?

2. Insofar as secondary effects of social origins do still operate, are they associated with the different components of social origins that we distinguish in the same or in different ways as are primary effects?

The further question of how far the results we report are in some degree specific to the English educational system or are of more general applicability is one for subsequent research.

\section{DATA AND VARIABLES}

\section{1 | Data}

The Longitudinal Study of Young People in England (LSYPE) is our data source. ${ }^{3}$ The study, started in 2004, is based on a nationally representative sample of more than 15,000 students born between September 1989 and August 1990. These students were first interviewed when aged 13-14 and were repeatedly re-interviewed, in some cases along with their parents, until they were aged 25-26. Interview data in various respects have been supplemented with information from administrative sources.

The LSYPE sample has a multi-stage stratified design. Schools were the primary sampling units. A sample of schools was drawn from the Pupil Annual School Leaving Census and the School Level Annual School Census which cover all state-funded, schools, and all "independent"-or fee-levying-schools in England, except for those with fewer than 10 "Year 9" (i.e., 13-14 years old) pupils and those having only boarding pupils. State schools were stratified into "deprived" and "non-deprived," based on the proportion of pupils in receipt of free school meals, with the former being over-sampled. In the second stage of sampling, an average of 33 pupils were selected from each school, with certain ethnic minority groups being over-sampled. At the school level, the survey achieved a $73 \%$ response rate, and at the pupil level, a $74 \%$ response rate, leading to a sample of 15,770 individual respondents. However, we base most of our multivariate analyses on a reduced sample of 9,171 respondents, for whom we have full information on their social origins and educational careers, as shown in online Appendix Table 1. In all analyses, we use weights in order to take account of survey attrition and non-response as well as of the stratification of the sample. 


\section{2 | Variables}

\subsection{1 | Educational transitions}

The ultimate dependent variables of our analyses are five educational transitions that students may, or may not, make within the academic track of the English educational system. ${ }^{4}$ Their prior educational performance is in some instances a further dependent variable in relation to the independent variables of social origins, but in other instances it becomes a further independent variable, together with social origins, in relation to educational transitions.

For each transition we have a binary variable to capture whether or not the transition was made. The first three transitions are: continuing from GCSEs to upper secondary education to take A-level courses, applying to university, and entering university. In this latter case, we further distinguish gaining access to an elite-"Russell Group"-university. The final transition is then that of going on from undergraduate to postgraduate study. It should be noted that while GCSE results are a factor in continuation to A-levels, and A-level results a factor in continuing to university, they do not operate as formal selection instruments: some significant degree of flexibility and thus of choice exists. As earlier noted, the English educational system is one characterized by both relatively weak stratification and selectivity. Table 1 shows the proportions of respondents who had made each of the five transitions by age $26 .^{5}$

\subsubsection{Educational performance}

Students' prior educational performance is, as said, in some instances a further dependent variable in relation to the independent variables of social origins, but in other instances it becomes a further independent variable, together with social origins, in relation to educational transitions.

We first of all construct a variable that aims to capture respondents' demonstrated academic ability in childhood. In the LSYPE dataset scores are available from the "Key Stage 2" (KS2) attainment test that children take at age 11. These scores refer to performance in English (reading, grammar, punctuation, and spelling), mathematics, and science. It has been shown that they correlate highly with standard cognitive ability test scores and also with individuals' subsequent GCSE performance (Strand, 2006). In the first column of Table 2, which gives information on the distributions of all our performance variables, we show approximate ability quartiles derived from a principal components analysis of KS2 scores.

We then create two further variables to measure respondents' academic performance preceding the five transitions. The first measures respondents' GCSE performance. We start with the total number of A*-C, or "good," grades that a student achieved, but in order to take account of differences in grades, we weight these following a system introduced in 2017 that scores grades on a 9-1 points scale (Ofqual, 2018). Online Appendix Figure 1.1 plots the cumulative distribution of this measure alongside the distribution of the unweighted variable. When, on the basis of our weighted measure, we form approximate quartiles, it can be seen, from the second column of Table 2, that the "profiles" of those included are distinctive. In the top quartile all students have at least one GCSE

TAB LE 1 Proportion (\%) of respondents making five educational transitions by age 26

\begin{tabular}{|llllll} 
& $\begin{array}{l}\text { Continuing to } \\
\text { A-level }\end{array}$ & $\begin{array}{l}\text { Applying to } \\
\text { university }\end{array}$ & $\begin{array}{l}\text { Entering } \\
\text { university }\end{array}$ & $\begin{array}{l}\text { Accessing Russell } \\
\text { Group university }\end{array}$ & $\begin{array}{l}\text { Continuing to } \\
\text { postgraduate studies }\end{array}$ \\
\hline Proportion & 60.4 & 47.7 & 37.9 & 9.7 & 9.9 \\
\hline N & 9,502 & & & & \\
\hline
\end{tabular}


TAB LE 2 Approximations to quartiles (\%) and profiles of measures of educational performance at different points of respondents' school careers

\begin{tabular}{|c|c|c|c|c|c|c|c|c|c|c|c|c|}
\hline \multirow{3}{*}{$\begin{array}{l}\text { Approximation } \\
\text { to quartiles }\end{array}$} & \multirow{3}{*}{$\frac{\mathrm{KS} 2^{(\mathrm{a})}}{\%}$} & \multicolumn{5}{|c|}{$\operatorname{GCSE}^{(\mathrm{b})}$} & \multicolumn{6}{|c|}{ A-level ${ }^{(c)}$} \\
\hline & & \multicolumn{4}{|c|}{ Profile-Number of: } & \multirow[t]{2}{*}{$\%$} & \multicolumn{4}{|c|}{ Profile-Number of: } & \multirow[t]{2}{*}{$\%^{(\mathrm{d})}$} & \multirow[t]{2}{*}{$\%^{(\mathrm{e})}$} \\
\hline & & $A^{*}-A$ & B & $\mathrm{C}$ & $\%$ & & $A^{*}-A$ & B & C or D & $\%$ & & \\
\hline \multirow[t]{4}{*}{ Top } & \multirow[t]{4}{*}{26} & $5+$ & $0 / 1+$ & 0 & 40 & \multirow[t]{4}{*}{26} & $3+$ & $0 / 1+$ & $0 / 1+$ & 53 & \multirow[t]{4}{*}{25} & \multirow[t]{4}{*}{9} \\
\hline & & $5+$ & $0 / 1+$ & $1+$ & 25 & & $1-2$ & $0 / 1+$ & $0 / 1+$ & 30 & & \\
\hline & & \multirow[t]{2}{*}{$1-4$} & \multirow[t]{2}{*}{$0 / 1+$} & \multirow[t]{2}{*}{$0 / 1+$} & \multirow[t]{2}{*}{35} & & 0 & $3+$ & $0 / 1+$ & 8 & & \\
\hline & & & & & & & 0 & $1-2$ & $0 / 1+$ & 9 & & \\
\hline \multirow[t]{5}{*}{ Next-to-top } & \multirow[t]{5}{*}{25} & & & & ..(f) & \multirow[t]{5}{*}{25} & $1-2$ & $0 / 1+$ & $0 / 1+$ & 54 & \multirow[t]{5}{*}{26} & \multirow[t]{5}{*}{9} \\
\hline & & $1-4$ & $0 / 1+$ & $0 / 1+$ & 52 & & 0 & $3+$ & $0 / 1+$ & 12 & & \\
\hline & & 0 & $5+$ & $0 / 1+$ & 10 & & 0 & $1-2$ & $0 / 1+$ & 28 & & \\
\hline & & 0 & $1-4$ & $0 / 1+$ & 34 & & & & & ..(f) & & \\
\hline & & & & &..$(f)$ & & & & & & & \\
\hline \multirow[t]{3}{*}{ Next-to-bottom } & \multirow[t]{3}{*}{24} & $1-4$ & $0 / 1+$ & $0 / 1+$ & 13 & \multirow[t]{3}{*}{23} & & & & ..(f) & \multirow[t]{3}{*}{24} & \multirow[t]{3}{*}{9} \\
\hline & & 0 & $1-4$ & $0 / 1+$ & 44 & & 0 & $1-2$ & $0 / 1+$ & 51 & & \\
\hline & & 0 & 0 & $1+$ & 43 & & 0 & 0 & $1+$ & 42 & & \\
\hline \multirow[t]{3}{*}{ Bottom } & \multirow[t]{3}{*}{24} & & & &..$(f)$ & \multirow[t]{3}{*}{26} & 0 & $1-2$ & $0 / 1+$ & 10 & \multirow[t]{3}{*}{25} & 9 \\
\hline & & 0 & 0 & $1+$ & 34 & & 0 & 0 & $1+$ & 90 & & \\
\hline & & 0 & 0 & 0 & 62 & & & & & & & \\
\hline $\begin{array}{l}\text { No A-level } \\
\text { graded } A^{*} \text {-D or } \\
\text { no progression } \\
\text { to A-level }\end{array}$ & & & & & & & & & & & & 64 \\
\hline Total & 100 & & & & & 100 & & & & & 100 & 100 \\
\hline$N$ & 8,703 & & & & & 9,171 & & & & & 3,277 & 9,171 \\
\hline
\end{tabular}

Note: (a) Principal Component Analysis (PCA) values of Key Stage 2 test results in English, Mathematics and Science.

(b) Weighted number of GCSEs. Weights: $A^{*}-A=7.5 ; B=6 ; C=4 ; D-G=1$ (approximating the "9-1" grading schema).

(c) Weighted number of $A$-level passes graded $A^{*}-D$. Weights: $A-A^{*}=55, B=40, C=30, D=20$.

(d) Among those who achieved at least one A-level graded $A^{*}$-D.

(e) In the whole sample.

(f) Not reported to preserve anonymity.

graded $A^{*}-A$, and $65 \%$ of them have five or more. In contrast, in the bottom quartile there is no respondent with a GCSE graded $A^{*}-A$, and the majority do not have any good GCSEs at all.

Our second variable captures the performance of those who went on to upper secondary education and achieved at least one "good" A-level (i.e., graded A*-D) $-36 \%$ of all respondents. Again, we first take the total number of good A-levels achieved, and then apply a weight based on the U.K. Department for Education "Performance Table Point Scores for Level 3 Qualifications," giving higher points to those with better grades (Department for Education, 2019). Online Appendix Figure 1.2 plots the cumulative distributions of our unweighted and weighted measures. From our weighted measure we again derive approximate quartiles, as shown in the third column of Table 2 along with the differing profiles of their members. Of those in the top quartile only $17 \%$ do not have any Alevel graded $A^{*}-A$, and more than half of them have three or more. In contrast, among those in the bottom quartile the vast majority only have $\mathrm{A}$-levels graded $\mathrm{C}$ or lower. 


\subsection{3 | Social origins}

Since we are interested in the relative importance in individuals' educational attainment of primary and secondary effects in relation to different components of their social origins, we need to have social origin variables that are comparable in form. For this reason, we seek to construct our social origin variables, like our performance variables, as quartiles, even though in some cases the approximations are less good on account of the "lumpiness" of the original distributions. We create these distributions from data in waves 1 and 2 of LSYPE, which occurred when respondents were 13-15 years old.

Parental class is measured by the British National Statistics Socio-Economic Classification (NS-SEC), in which class position is determined by occupation and employment status. We use the "reduced" method of allocation (Office for National Statistics, 2005: Table 17). We begin with the seven-category version as shown in Table 3. Where both parents are in employment and can therefore be allocated to a class, we use the dominance method of determining parental class (Erikson, 1984). Then, from the distribution of the seven-category variable, we approximate parental class quartiles, as also shown in Table 3. As can be seen, the top quartile is made up by Class 1 , the next-to-top by Class 2, the next-to-bottom by Classes 3, 4, and 5, and the bottom by Classes 6 and 7.

Our parental income variable captures parents' total income from work, benefits, and any other source. Parents were asked to indicate their annual joint income within a list of 32 bands, and those who selected the highest band were further asked to indicate, from a list of 60 high-income bands, into which of these their income fell. We have thus in all 91 income categories. To achieve comparability with official statistics, the upper and lower bounds of these categories were transformed into weekly amounts, and, in each case, an income figure was taken from the mid-value. ${ }^{6}$ We then construct parental income quartiles.

We measure parental status by the status scale developed by Chan and Goldthorpe (2004), based on the occupational structure of close friendship. Respondents' parents were coded to the 31 categories of the scale, and where they fell into different categories, parental status was determined by taking the higher-ranking category. Parental status quartiles are then approximated on the basis of these rankings.

Parental education is treated through a version of a qualifications scale, combining both father's and mother's qualifications, that was developed in previous work (Bukodi \& Goldthorpe, 2013). The seven-category scale is shown in Table 4 and, based on parents' distribution over these categories, parental educational quartiles are approximated (see further Zhao \& Bukodi, 2020).

In the upper panel of Table 5 we show the approximations to quartiles of all four social origin variables, and in the lower panel their rank correlations. As can be seen, the correlations are, overall, quite modest, the lowest being those between parental income and parental status and education, and the highest being those between

TAB LE 3 Distribution (\%) of parental class-seven-category NS-SEC ${ }^{(a)}$

Parental NS-SEC
Class 1: Higher managerial and professional
Class 2: Lower managerial and professional
Class 3: Intermediate
Class 4: Small employers and own account workers
Class 5: Lower supervisory and technical
Class 6: Semi-routine
Class 7: Routine
Total
$N$

Note: (a) Dashed lines indicate approximation to quartiles. 
TABLE 4 Distribution (\%) of parental education ${ }^{(a)}$

\begin{tabular}{lc}
\hline Parental education & $\%$ \\
\hline (1) Both parents have university-level qualifications & 9.8 \\
\hline (2) One parent has university-level qualification; other parent has lower qualification & 10.9 \\
\hline (3) Both parents have upper secondary or lower tertiary qualification & 10.6 \\
\hline (4) One parent has upper secondary or lower tertiary qualification; other parent has lower qualification & 13.3 \\
\hline (5) Both parents have lower secondary or other qualifications & 34.3 \\
\hline (6) One parent has lower secondary or other qualification; other parent has no qualification & 12.8 \\
\hline (7) Neither parent has any qualification & 8.3 \\
\hline Total & 100.0 \\
\hline$N$ & 9,502 \\
\hline
\end{tabular}

Note: (a) Dashed lines indicate approximation to quartiles.

TAB LE 5 Four components of social origins-approximations to quartiles (\%) and rank correlations

\begin{tabular}{|c|c|c|c|c|}
\hline & \multicolumn{4}{|c|}{ Parental } \\
\hline & class & Income & status & education \\
\hline Approximation to quartiles & \multicolumn{4}{|c|}{ Distribution (\%) } \\
\hline Top & 17.9 & 29.9 & 28.0 & 20.7 \\
\hline Next-to-top & 30.4 & 25.2 & 23.0 & 23.9 \\
\hline Next-to-bottom & 28.9 & 24.1 & 26.1 & 34.3 \\
\hline Bottom & 22.8 & 20.8 & 22.9 & 21.2 \\
\hline Total & 100.0 & 100.0 & 100.0 & 100.1 \\
\hline Parental & \multicolumn{4}{|c|}{ Rank correlations } \\
\hline Class & 1 & 0.44 & 0.68 & 0.54 \\
\hline Income & & 1 & 0.39 & 0.38 \\
\hline Status & & & 1 & 0.57 \\
\hline Education & & & & 1 \\
\hline$N$ & 9,502 & & & \\
\hline
\end{tabular}

parental class and parental status. But even in this latter case, no problems of multicollinearity arise in our analyses. ${ }^{7}$ The importance of our multidimensional approach to social origins is thus underlined.

Our interest in this paper is not in gender differences, and we do not therefore report separate analyses for men and women, but we do include gender as a control in all of our models. No consistent differences by gender in fact show up in our analyses, with one exception that we later discuss.

\section{3 | RESULTS}

We present the results of our analyses in accordance with the two research questions that we previously set out. The first is whether in England the secondary effects of social origins still operate, in addition to primary effects, in creating disparities in the transitions that young people do or do not make in their educational careers. 
We begin with some descriptive statistics. Figure 1 shows the proportions of respondents who, by age 26 , have made the five educational transitions that we consider in relation to their GCSE performance, and separately for those with parents in the top and bottom quartiles of class, income, status, and education.

As is apparent from Figure 1-and as might be expected-how well students do in GCSE examinations makes a large difference to their probability of going on to a higher level of education, and in particular as regards the first three transitions that we distinguish: continuing to A-levels, applying to university, and entering university. For these transitions, differences between top and bottom quartile performers can be as large as 80 percentage

Continuing to A-level

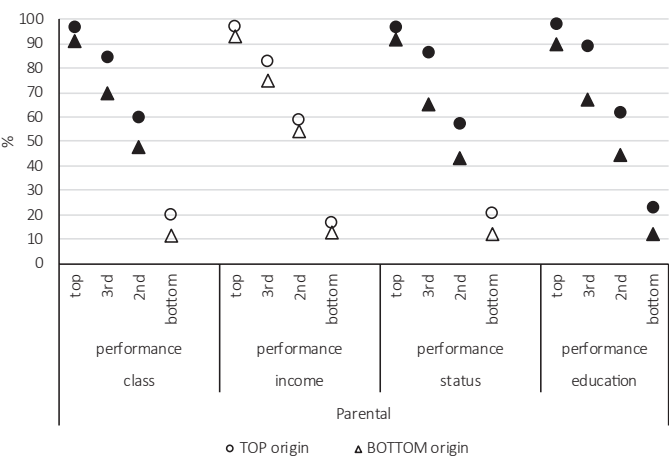

Entering university

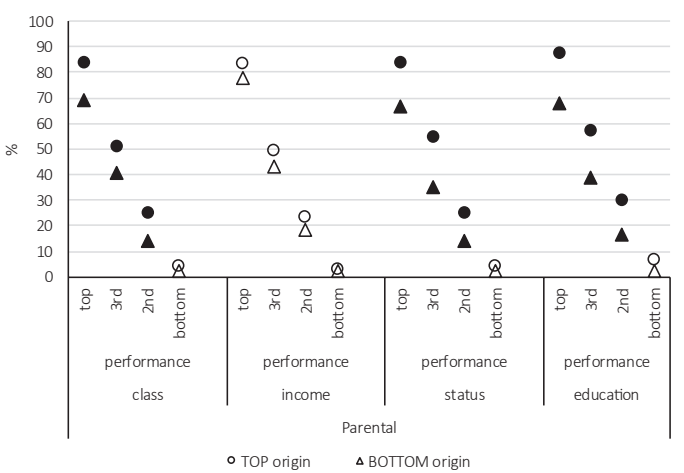

Continuing to postgraduate studies

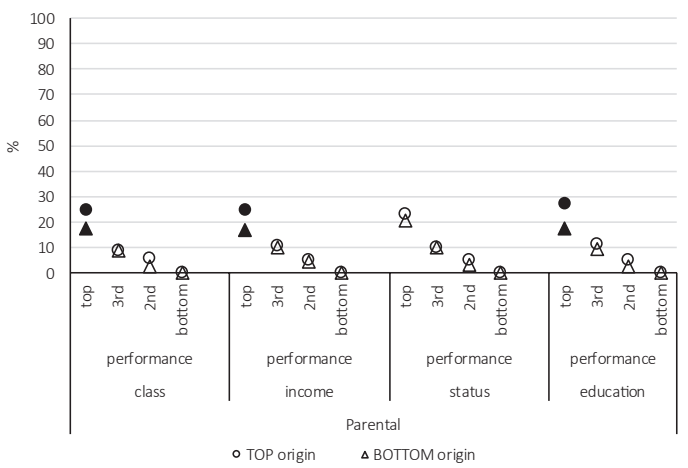

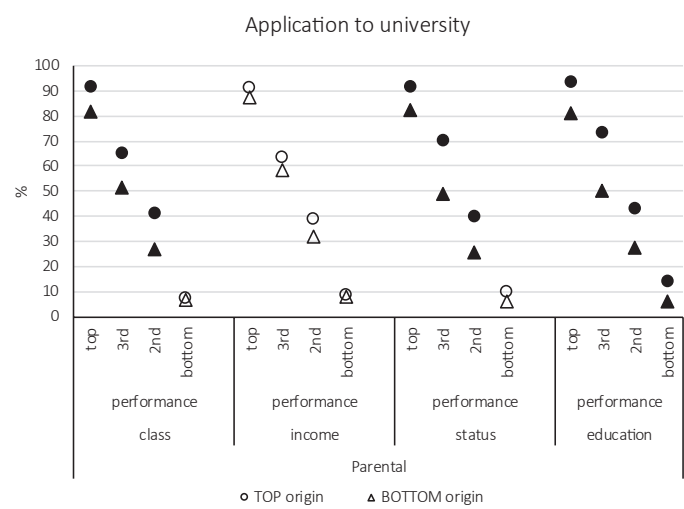

Accessing elite university

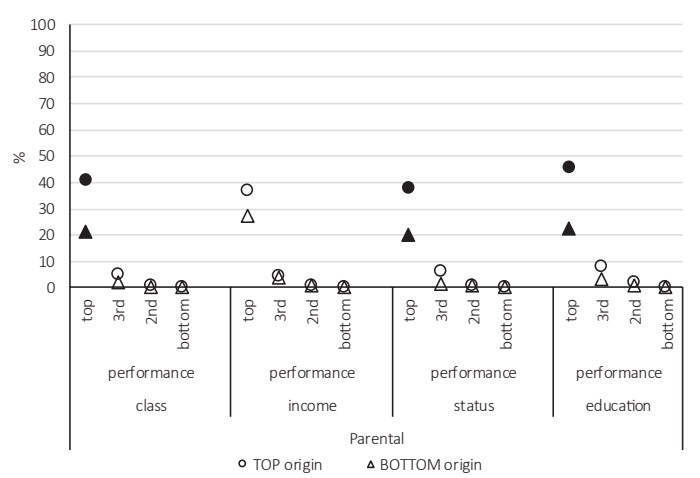

FIGURE 1 Proportion (\%) of respondents who have made the five educational transitions by level of GCSE performance and social origins ${ }^{(a)}$

(a) Filled symbols: statistically significant difference between respondents from top and bottom quartiles of social origin variables. Hollow symbols: no statistically significant difference between respondents from top and bottom quartiles. 


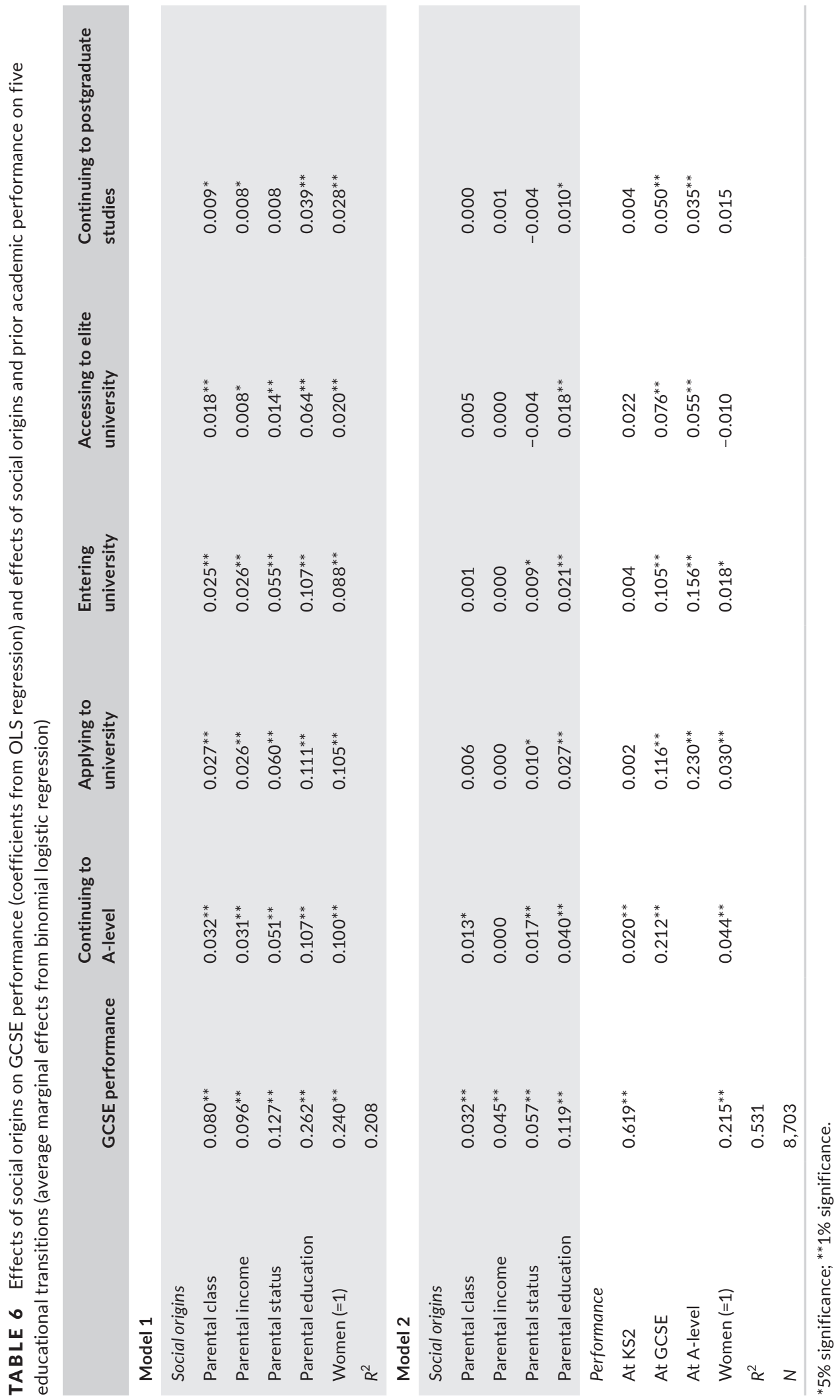


points. As regards accessing an elite university or going on to postgraduate study, disparities related to GCSE performance are smaller and chiefly show up between the top quartile performers and the rest. However, and most relevant for our present purposes, Figure 1 indicates that social origins do also matter. At any given level of GCSE performance, children with parents in the most advantaged quartile, in terms of class, status, or educationthough, notably, not of income-are regularly more likely than children with parents in the least advantaged quartile to make any of the five transitions in question. With the first two transitions, such disparities by social origins are most pronounced for middling level performers: those with the most advantaged parents are around 15-20 percentage points more likely to continue to A-levels, and then to apply to university, than those with the least advantaged parents. In contrast, in the case of accessing an elite university, or going on to postgraduate study, social origin disparities are essentially confined to top quartile performers.

Figure 1 then suggests that secondary effects still operate in the English educational system. But we now need to ask what happens if in our analyses we include all measures of prior academic performance and all four components of social origins in full and simultaneously.

We run a series of binomial logistic regression analyses, in which the key dependent variable is whether respondents did, or did not, make a particular educational transition (supplemented by a linear regression where individuals' GCSE performance is the dependent variable). The independent variables are our four measures of social origins and relevant indicators of prior academic performance. All independent variables are introduced in continuous and normalized form. Table 6 reports the results.

Model 1 reveals, in line with earlier findings (e.g., Bukodi et al., 2014, 2017), that all four components of social origins-parental class, income, status, and education-have statistically significant independent effects on individuals' GCSE performance and on their probabilities of making subsequent educational transitions. But it is also apparent that the probability of making each of the five transitions is more strongly associated with parental education than with parental class, income, or status. ${ }^{8}$

With Model 2, we then introduce our three indicators of prior academic performance into the analysis. As would be expected, these have, in most cases, significant and large effects on educational transitions, although there are variations across transitions in their relative importance. For example, in the case of applying to and then entering university, good A-level performance is more important than good GCSE performance, while for accessing an elite university or going on to postgraduate studies good GCSEs apparently count for more. ${ }^{9}$ However, what further emerges from Model 2 is that the effect of parental education and, at all except the two last transitions, the effect of parental status remain statistically significant, even though reduced in size by around $70 \%-75 \%$ from Model 1. In other words, these results confirm the indications from Figure 1 that secondary effects of social origins do continue to operate, although largely associated with differences in what may be thought of as parents' specifically educational and more general sociocultural resources rather than with their economic resources. Insofar as parental class and parental income affect children's educational attainment, they do so mainly via academic performance at lower secondary, GCSE, level-or, that is, as a primary effect.

Finally, Model 1 also shows that women, overall, are more likely than men to make the educational transitions that we consider. But, as Model 2 reveals, with the two last transitions, accessing an elite university and continuing to postgraduate study, the main reason for this would appear to be that women outperform men at earlier stages of their educational careers: that is, once we control for their prior performance, women's advantage in these transitions disappears.

We now turn to our second research question. Given that secondary effects of social origins do still operate, what is their importance in educational transitions relative to that of primary effects, and are primary and secondary effects associated in similar or in different ways with the different components of social origins that we distinguish?

In the foregoing, we have sought to establish the presence of secondary effects by showing disparities in the educational transitions made by young people of different social origins when their prior academic performance is held constant. In focusing now on the relative importance of primary and secondary effects, we need to pursue 
a more complex form of analysis to take account of all the joint relationships that are involved. We conceptualize these relationships in the form of an "origins-prior performance-transition" (OPT) triangle. This approach has proved useful in earlier research in examining the extent to which the effects of social origins on educational attainment are mediated via individuals' early life cognitive ability (Bourne et al., 2018). Here, we ask how far educational transitions are mediated via prior educational performance.

We work with the analytical model shown in Figure 2. We decompose the total effects on transitions of our four social origin variables, when included in the analyses simultaneously, into indirect paths that go via prior performance-that is, primary effects ${ }^{10}$-and into direct paths that are not mediated by prior performance-that is, secondary effects.

Since our dependent variables are binary, we use a nonlinear probability model. With such a model, partitioning the total effects of social origins into indirect and direct paths is not as straightforward as it would be in the linear case. Coefficients for the variables of interest may be affected not only by the inclusion of other variables in the model with which they are correlated, but also by residual variance, which is not independently identified and changes in response to alterations in model specification (see, e.g., Kohler et al., 2011; Winship \& Mare, 1984). We seek to overcome these difficulties using the KHB method of nonlinear decomposition (Karlson et al., 2012; and see further Breen et al., 2018) which provides a way of separating mediating from "rescaling" effects when comparing conditional and unconditional parameter estimates.

We present the results from our decomposition analyses, for each educational transition, in Figures 3-7. The left-hand panel of these figures shows the coefficients-that is, log-odds ratios-along with $95 \%$ confidence intervals for the primary effects (hollow triangles and squares) and for the secondary effects (filled circles) of social origins, separately for the four components. The right-hand panels then show the "cumulative" primary, secondary, and total effects of social origins, calculated by adding up all the respective individual coefficients given in the left-hand panel-that is, eight coefficients for primary effects and four coefficients for secondary effects. These cumulative effects are presented, using different hatchings and shadings, for the four social origins components

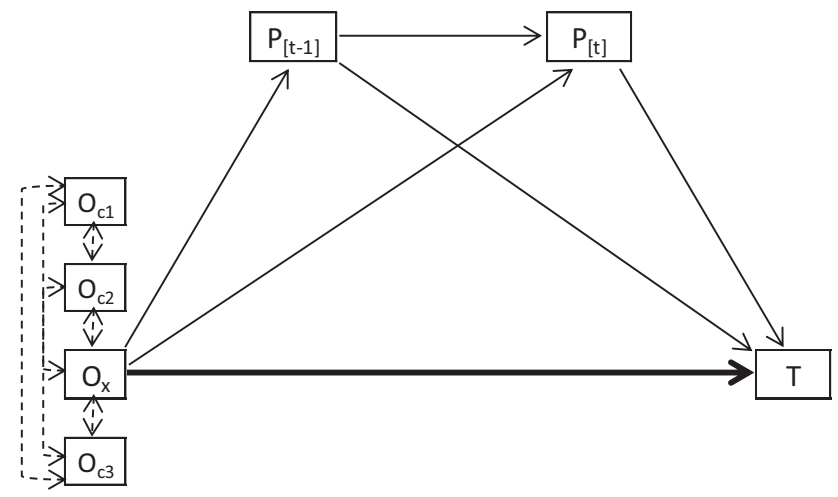

Notes

$\mathrm{O}_{\mathrm{x}}$ : social origin component to be decomposed

$\mathrm{O}_{\mathrm{ci}}$ : other social origin components acting as controls

$\mathrm{T}$ : educational transition

$\mathrm{P}[\mathrm{t}]$ : academic performance immediately preceding educational transition

$\mathrm{P}[\mathrm{t}-1]$ : earlier academic performance

$\rightarrow$ Primary effect

Secondary effect

FIGURE 2 Analytical model for decomposing the effects of social origins into primary and secondary effects 

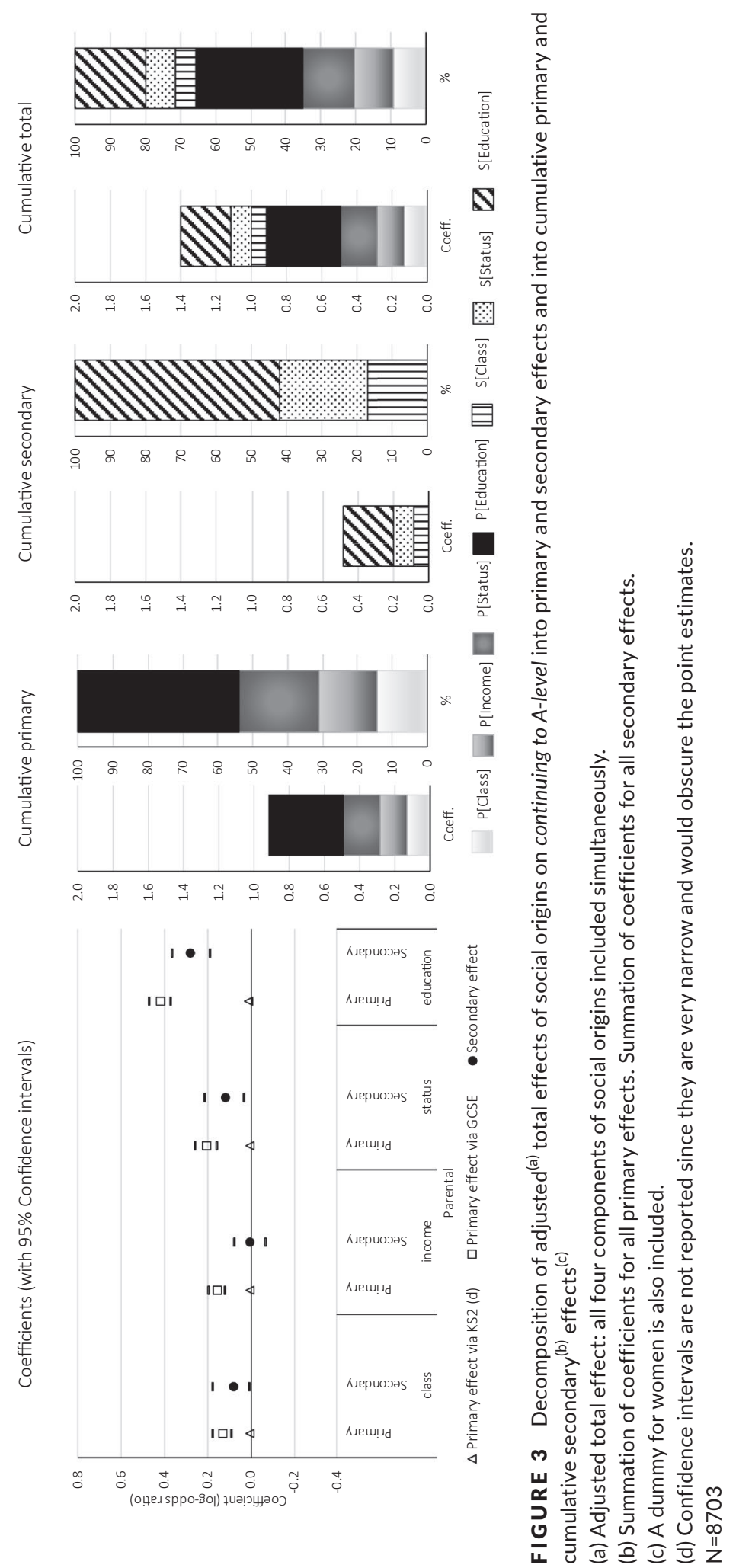

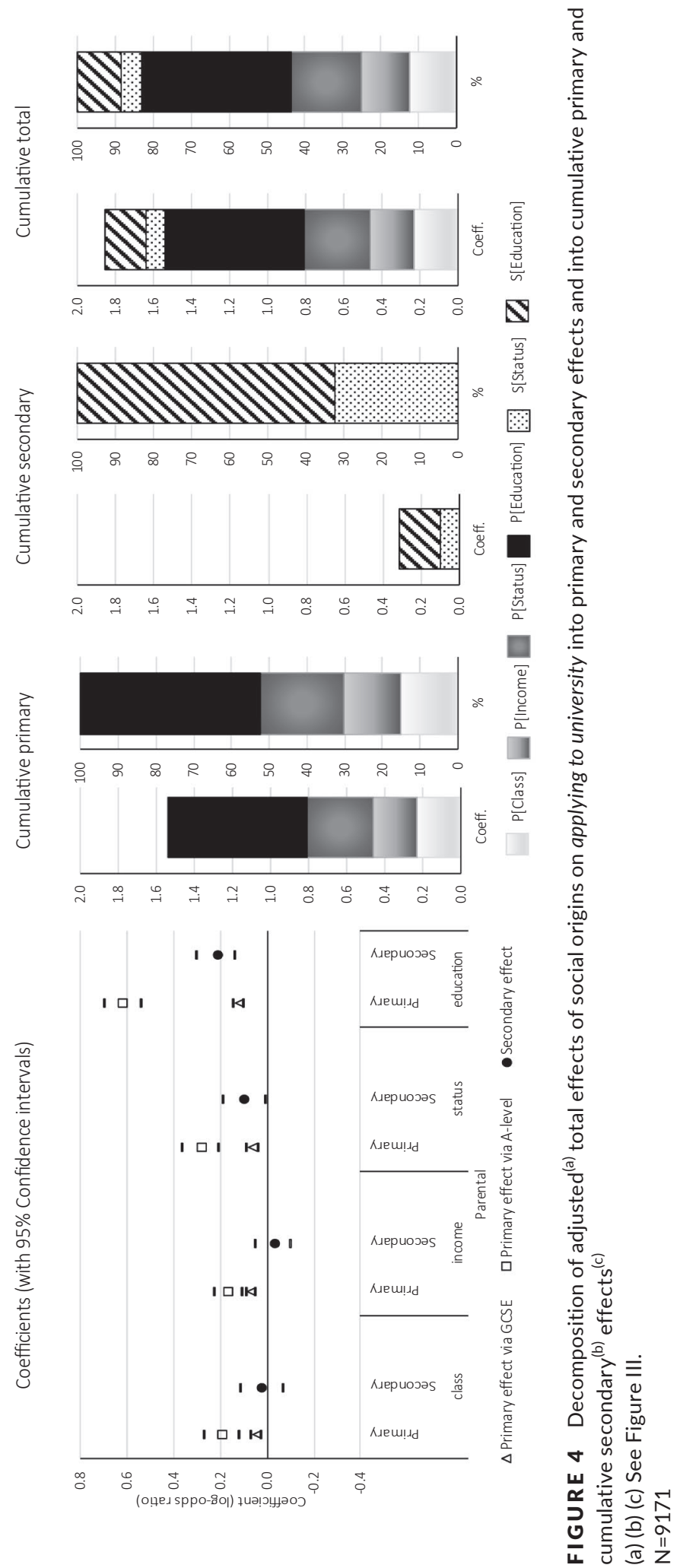

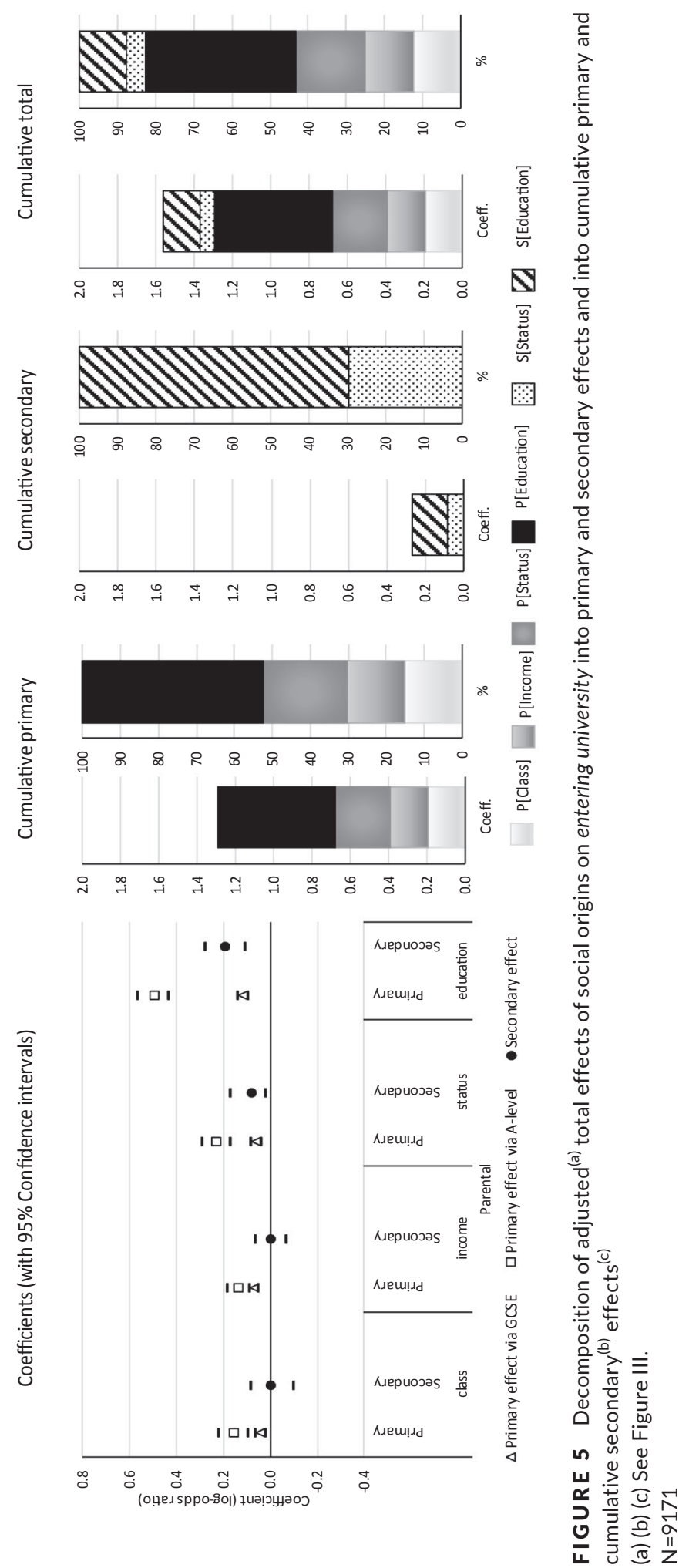


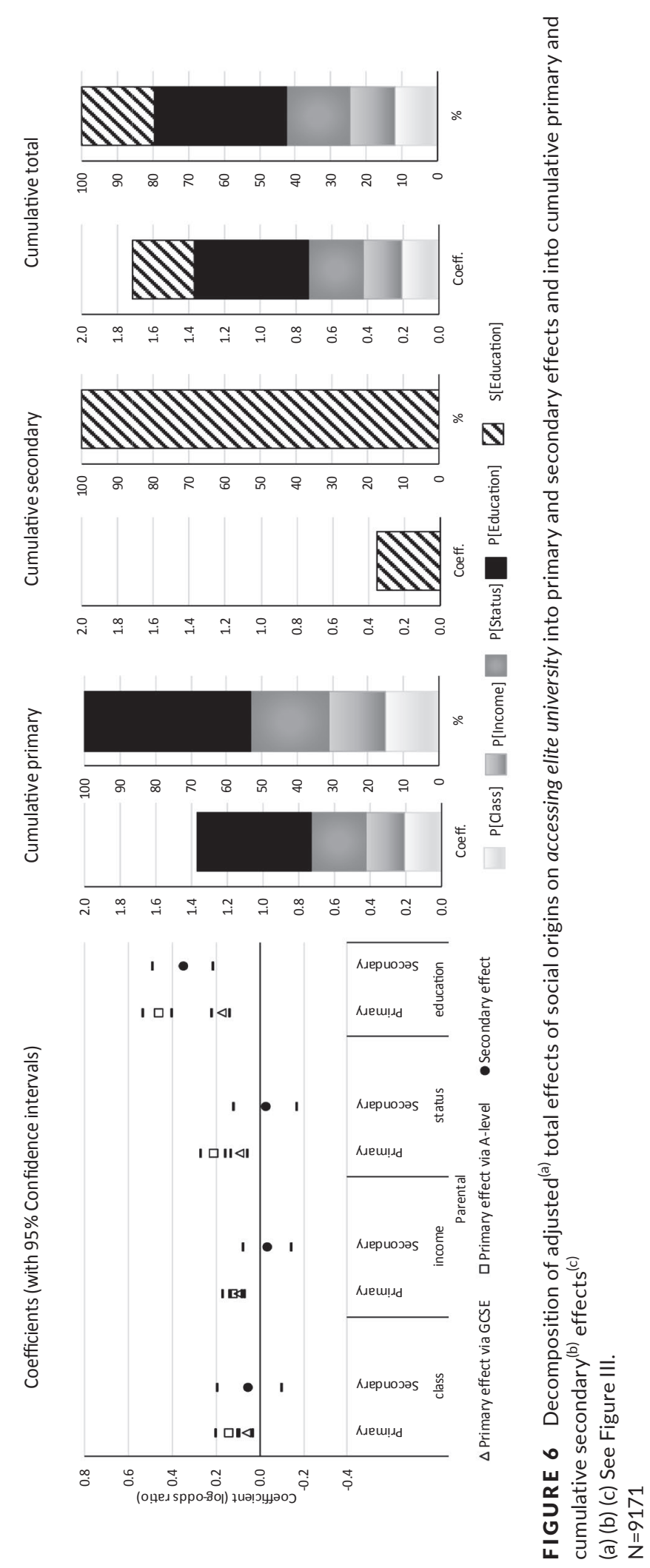



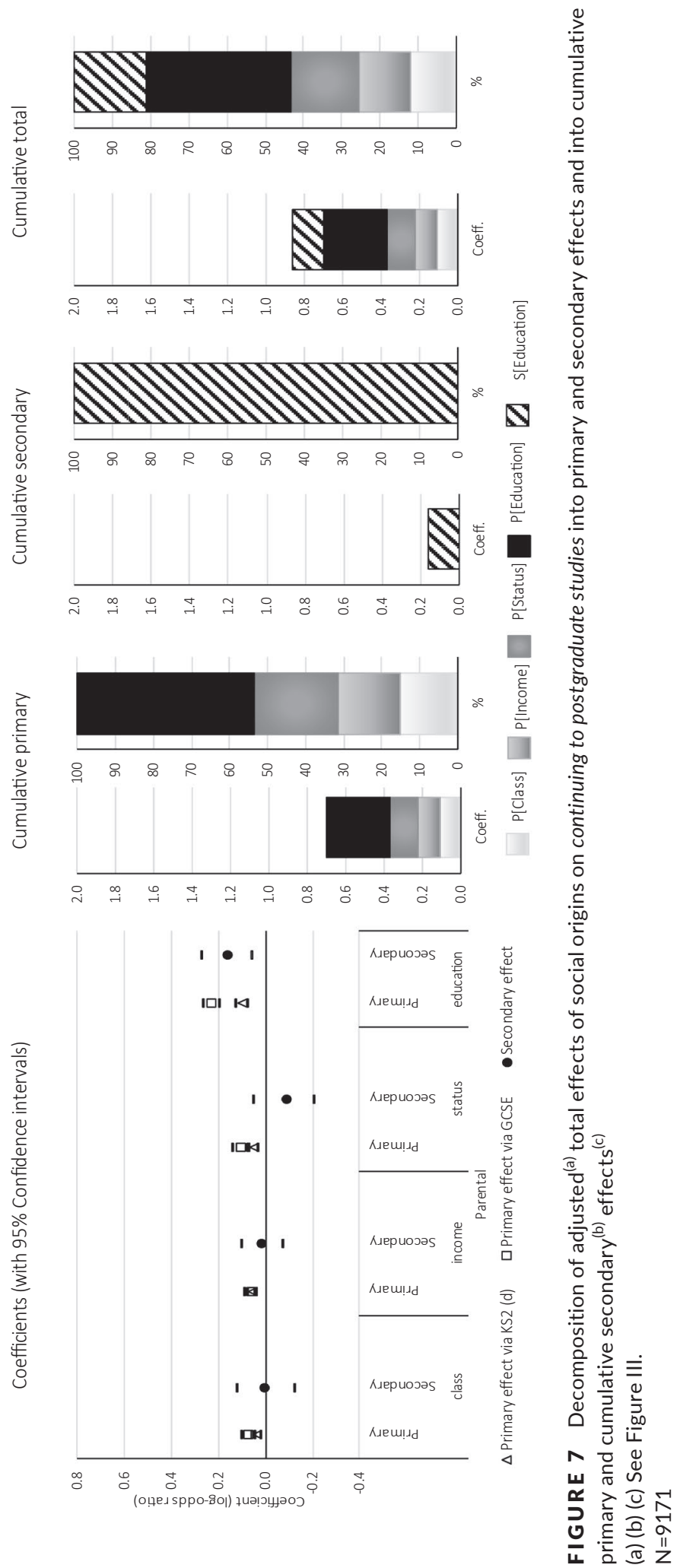
and for primary and secondary effects in both an absolute form-showing the summed coefficients themselvesand in a relative, percentage form.

Starting with the results for the transition to A-level, as shown in Figure 3, it is clear from the left-hand panel that parental class, income, status, and education are all related to the probability of students making this transition. But, in line with what we have shown in Table 6, parental income operates only via primary effects-that is, through its association with prior academic performance. When we consider all four social origin components together, it can be seen from the Cumulative Total columns in the right-hand panel that as much as $35 \%$ of the cumulative total effect of social origins is secondary or, in other words, is not mediated through prior academic performance, as against $65 \%$ that is so mediated. And, it is further apparent from the Cumulative Secondary columns that this secondary effect is largely associated with either parental education-around $60 \%$-or parental status-over 20\%. The Cumulative Primary columns show that a large part of this effect also is associated with parental education-over 45\%-and with parental status-almost 25\%. But here parental class and income do appear of some importance, each being associated with around $15 \%$ of the primary effect.

Turning now to the probability of applying to university, it is apparent from Figure 4 that secondary effects are in this case less important than with the transition to A-level, although still far from negligible: some $17 \%$ of the cumulative total effect of social origins is not mediated through prior academic performance. As regards the pattern of associations with components of social origins, a more extreme version emerges than what was seen with the A-level transition. Secondary effects are close to $70 \%$ associated with parental education and $30 \%$ with parental status, leaving parental class, and parental income of no importance. However, as regards the pattern of association with primary effects, there is a close similarity between university application and A-level transition.

In Figures 5-7 results in the same form are presented for the three remaining transitions that we considerentering university, accessing an elite university, and progressing to postgraduate study. These results prove to be for the most part on the same lines as those shown for applying to university in Figure 4 . With each transition, $15 \%-20 \%$ of the total cumulative effects of social origins is secondary and thus $80 \%-85 \%$ primary. The reduced importance of secondary effects at these later transitions we would see as resulting from the fact that seeking and gaining entry to a university and going on to postgraduate work are all more closely governed by previous performance than is making the transition from GCSEs to A-levels. As earlier noted, it is in general the case that insofar as in educational systems selectivity based on performance prevails, secondary effects will be limited.

As regards the patterns of association with components of social origins that are revealed in the last three transitions, these are for primary effects essentially the same as those shown for the earlier ones. But with secondary effects two notable differences occur. While in the case of entering university, the pattern is the same as with applying to university-that is, $70 \%$ of the secondary effect is associated with parental education and $30 \%$ with parental status -in the cases both of accessing an elite university and going on to postgraduate study, it would appear that the entire secondary effect operates via parental education (see Triventi, 2013, for similar cross-national findings).

In sum, with all five educational transitions that we consider, we find that, although the secondary effects of social origins are clearly smaller than the primary effects, they are still of importance. At the A-level transition, around a third, and at the other transitions up to a fifth of the effects of social origins are secondary. ${ }^{11}$ We further find marked similarities across educational transitions in the pattern on which primary and secondary effects are associated with different components of social origins, indicative of different kinds of parental resources. We see around a third of the primary effects of social origins as being channeled via parents' economic resources, as indicated by their class and income, and around two-thirds via their sociocultural and specifically educational resources as indicated by their status and education. But so far as the secondary effects of social origins are concerned, the importance of family educational and sociocultural resources appears quite predominant in all transitions. ${ }^{12,13}$ 


\section{4 | CONCLUSIONS}

To sum up our findings in regard to the two research questions that we have posed, we would say the following.

First, in England the secondary effects of social origins-their effects via the educational choices that young people make, given their prior academic performance-do still operate in key educational transitions. But, as a result of distinguishing different components of social origins, it is also evident from our analyses that such effects are predominantly associated with parents' education and status rather than with their class or income. This reinforces the suggestion earlier made that the failure of Chowdry et al. (2013) to find any secondary effects of importance in the transition to university is the result primarily of their treatment of social origins. Not only are these authors limited by their data source to very weak measures but those that they are able to use are ones far more likely to pick up family economic rather than educational or other sociocultural resources. And, our findings do of course in turn suggest that policy aimed at reducing educational inequalities should not focus solely on the primary effects of social origins but on their secondary effects also; and choice may in fact be more readily influenced than performance.

Second, while the primary effects of social origins are clearly more important than secondary effects in creating disparities in educational transitions, our mediation analyses establish that the latter are still of real consequence. In the case of disparities in the transition to A-levels, we estimate that as much as $35 \%$ of the total effect of social origins is secondary-that is, is not mediated through prior academic performance. This proportion falls within the range of between a quarter and a half for this same transition suggested by Jackson et al. (2007) for three different years in the last quarter of the 20th century, while being higher than the more precise estimate of $16 \%$ made by Jackson (2013c) for the 1991 transition. But it has to be noted that in these studies social origins were treated on the basis of only parental class or only parental education, so comparisons are difficult. For the four subsequent transitions that we consider, the proportion of the total of social origin effects on disparities that is secondary lies between $15 \%$ and $20 \%$-smaller than with the A-level transition but still of evident importance. Furthermore, our mediation analyses confirm that with the A-level transition, and also with applying to and entering university, secondary effects are most strongly associated with parental education and then to a lesser degree with parental status, while little association exists with parental class and none at all with parental income. And in the case of accessing an elite university or of continuing to graduate study, it is through parental education alone that the secondary effect of social origins operates. Primary effects are also at all transitions most strongly associated with parental education and status but in this case both parental class and parental income do also retain some importance.

Given these empirical findings, on what basis might an explanation for them be sought? Two broad possibilities exist: an explanation in terms of individual attributes or an explanation in terms of social processes.

In the first case, the idea would be that certain individual attributes of a kind likely to influence educational choices are associated with social origins, and in such a way that young people of more advantaged origins are more likely to make more ambitious choices, given prior performance, than are those of less advantaged origins. However, relevant research does not provide much encouragement for this approach. Most notably, Breen et al. (2014) have shown, in the context of the Danish educational system, that while differences in students' levels of risk aversion and in their time-discounting preferences do have a significant relationship with their educational choices, these attributes play little part in mediating the effects of social origin variables on such choices. In fact, no association exists between these attributes and the choices made by students who are from the most advantaged socioeconomic backgrounds.

An approach in terms of social process-that is, of the actions and interactions of individuals-would seem more promising, and it is indeed through such an approach that most previous attempts have been made at explaining the existence of secondary effects in educational inequalities. From Boudon's own attempt (1974) through to those of Gambetta (1987), Erikson and Jonsson (1996), Goldthorpe (1996/2000), and Breen and Goldthorpe (1997), the central argument has been that young people, together with their parents and perhaps other family 
or friends, make educational choices on the basis of some kind of cost-benefit evaluation. They set the costs, including the opportunity costs, of staying on in education against the expected benefits of doing so, and especially benefits in regard to their future employment possibilities. Differences in choices, leading to secondary effects, then come about because for young people of more advantaged social origins the benefits of staying on and in general of making more ambitious educational choices, at almost any level of previous academic performance, tend to outweigh the costs involved far more often than for those of less advantaged origins. Crucial here is the fact that the more advantaged individuals' social origins are, the higher the level of educational attainment that is likely to be required in order to give them good chances of maintaining their parents' position. And, the primary motivation for those of advantaged origins to progress in the educational system as far as ever is possible can then be seen as that of avoiding downward social mobility. What is known to be the powerful force of loss aversion (Kahneman \& Tversky, 1979; Kahneman, 2011, ch. 26) comes into play. As Breen et al. suggest (2014, p. 266), in commenting on their finding of no relationship between risk aversion and staying on in education among students of more advantaged origins, "this arises because irrespective of risk tolerance" such students are always likely to stay on "as a way of ensuring that they reproduce their advantaged background." In other words, risk aversion as a personal attribute is overcome by loss aversion as defined in a social context.

However, while an explanation of the occurrence of secondary effects on these general lines might seem the best available, our results do point to the need for some further refinement. In the studies referred to above, in which social origins have been most frequently treated in terms of class, there is an at least implicit tendency to link secondary effects to the availability of greater economic resources. Young people whose parents have secure, stable, and steadily rising incomes are seen as better able to afford the costs of continuing in education and also likely to have better compensation available in the event of any failure-as, say, through being given "second chances." But what we now find is that, once a more comprehensive treatment of social origins is made, secondary effects prove to be far more closely associated with parental education and status than with parental class-or income. $^{14}$

What could then be hypothesized is that if it is indeed the threat of downward mobility that primarily drives secondary effects, it is downward mobility in terms of education and status, rather than of class or income, that are of chief concern. In particular, the children of graduate parents in high status professional occupations can be expected to be encouraged-and perhaps to come under some degree of pressure-to continue in their educational careers, and regardless, if possible, of their prior academic performance, until they have matched their parents' levels, while at the same time receiving all the support that their parents' experience and knowledge of how to progress in the educational system can provide. And as well as a university education being probably seen as of intrinsic value, it is of course also a prime requirement for access to professional employment, and thus for status maintenance too. A contrast is here implied not only with children of generally less advantaged social origins, for whom the educational and occupational requirements of avoiding downward mobility are less demanding, but also with those whose parents are in advantaged class positions with relatively high incomes, though positions with less than professional status and often achieved without the highest levels of educational attainment-as, say, business proprietors or managers in industry or services. In such cases, one might expect that children would be less likely to make progressive educational transitions where their previous performance did not give clear indications of future success, since other routes to reproducing their parents' position could be envisaged, and ones in regard to which their parents' resources could be more helpful than in an educational context.

Research designed to test what is hypothesized in the foregoing would, we believe, be the best way ahead in attempts to gain a fuller understanding of why the secondary effects of social origins continue, in England at least, to play a significant role in the creation of educational inequalities-and, on this basis, to devise appropriate policy. The primary effects of social origins are clearly the more important source of such inequalities. But the existence of secondary effects on the pattern we have reported implies that, as against the example set by children of highly educated professional parents, many other children of less advantaged origins are in effect still selling themselves 
short in their educational careers: that is, by opting not to continue when their previous performance would in fact give them a high probability of doing so successfully.

\section{DATA AVAILABILITY STATEMENT}

The data used in this study are available from the UK Data Archive through a secure access licence.

\section{ORCID}

Erzsébet Bukodi iD https://orcid.org/0000-0001-8277-2829

John H. Goldthorpe (iD https://orcid.org/0000-0003-1131-2619

\section{ENDNOTES}

${ }^{1}$ An unusual case is that of Italy where strong stratification coexists with weak selectivity. It is then found (Contini \& Scagni, 2013; Rees \& Azzolini, 2014) that secondary effects are the predominant source of social inequalities in educational attainment.

${ }^{2}$ For example, in the case of students in the lowest, least advantaged, quintile, $8 \%$ had mothers with a degree and $11 \%$ had fathers in higher managerial or professional occupations, while with those in the next-to-lowest quintile, these figures rise to $13 \%$ and $20 \%$, respectively (Chowdry et al., 2013: Table 3).

${ }^{3}$ University College London, UCL Institute of Education, Centre for Longitudinal Studies. (2018). Next Steps: Sweeps 1-8, 2004-2016: Secure Access. [data collection] 4th Edition. U.K. Data Service. SN: 7,104, http://doi.org/10.5255/ UKDA-SN-7104-4

4 The English system of vocational education and training is highly differentiated and complex (see Hansen \& Vignoles, 2005; Wolf et al., 2006). To study the operation of primary and secondary effects in this context would be extremely difficult and we do not attempt it here.

5 These proportions are broadly in line with figures from other data sources. For example, Murphy et al. (2019) report a university enrolment rate of around 38\% for individuals aged 19-23 in 2008-2009 (when most of the LSYPE respondents decided about higher education), based on the U.K. Labour Force Survey.

${ }^{6}$ As can be seen from online Appendix Table 1, it is with parental income that the problem of missing data is worst. We do not have information on 2,716 cases. The issue thus arises of how far this missingness is non-random with, say, low-income parents being under-represented. However, in our analytical sample the median value of gross weekly parental income is $£ 424.50$ and this is, reassuringly, very close to that of $£ 425.60$ gross weekly household income reported by the Expenditure and Food Survey for 2004-2005. It has been suggested that, in using LSYPE, children's eligibility for free school meals might provide a better indicator of families' economic resources than the income variable. However, we would note that apart from the former measure being only a binary one, it has been shown (Hobbs $\&$ Vignoles, 2010; Kounali et al., 2008) to have in fact only a quite loose relation with parental income or family economic conditions more generally.

${ }^{7}$ Furthermore, a one-way analysis of variance shows that parental class explains only $51 \%$ of the total variance of parental status.

8 In an auxiliary analysis-shown in online Appendix Figure 2-we show the extent to which the four components of social origin, when entered simultaneously in the analysis, "overlap" in their effects on children's educational transitions. As would be expected, overlaps occur in the case of all four components, but are of varying magnitude. For example, the unadjusted parental education effects are reduced by only $30 \%$ when the other components, most notably parental status, are included in the analysis. In contrast, the corresponding figures for parental class and parental income are substantially higher, at 70\%-75\%.

${ }^{9}$ We have no sure explanation of why this is the case but two possibilities are the following. First, it has been reported that some elite universities give at least as great weight to GCSE as to A-level results in their admissions procedures; and second, since in continuing to graduate studies-especially to masters degrees-students quite often change fields, GCSE results, covering a wider range of subjects than A-levels, could be regarded as more relevant.

10 In Table 6, the coefficients for KS2 performance are statistically insignificant for all educational transitions except for the transition to A-level. We, therefore, enter this variable in the analysis only in this latter case.

${ }^{11}$ In the case of the first three educational transitions, where the split between positive and negative responses is not more uneven than $20 \%-80 \%$, it is possible, as robustness check on our estimations of primary and secondary effects, 
to undertake path analyses through linear probability models (cf. Cox \& Wermuth, 1992). The results, available in online Appendix Figures 3.1-3.3, are very similar to those that we report in the text.

12 In online Appendix Figures 5.1-5.4, we have replicated the analyses presented above in Figures 4-7, but only for the "most eligible"-that is, for those who achieved at least one good A-level. As might be expected, the sizes of the total social origins effects are at all transitions significantly smaller than with our whole sample. However, secondary effects remain, and their importance relative to primary effects is actually larger, rather than smaller, than with the whole sample. Furthermore, the patterns of association between secondary effects and our four components of social origins are very similar to those shown in Figures 4-7, and this is largely so with primary effects also. The main exception is that the contribution of parental income is notably smaller, at only $4 \%-5 \%$, in line with our earlier observation that parents' income predominantly affects their children's application to, and entry into, university through its association with their performance at GCSE level.

${ }^{13}$ As we earlier pointed out, women are more likely than men to progress to higher levels of education, and the question might be raised of whether there are also differences between women and men in the relative importance of primary and secondary effects. We addressed this question in an auxiliary analysis (available in online Appendix Figures 4.14.5). Our results show that gender similarity is overall the prevailing pattern, although in certain transitions parental class appears to matter somewhat more for men and parental status somewhat more for women. Since with the dominance approach father's class tends to dominate mother's but mother's status tends to dominate father's (see Zhao \& Bukodi, 2020), it might be thought that this difference is an artefact of the approach. However, in a further analysis (available upon request), where we compare several different approaches to parental class and status, we show that this is not the case. And using the dominance approach leads in general to stronger associations between social origins and children's educational transitions, via both primary and secondary effects, than using either a father only or a mother only or a "combined" approach in which an equal weight is given to father's and mother's class or status.

${ }^{14}$ We should note that on one aspect of parents' economic resources we do lack information: that is, on their wealth. Pfeffer and Hällsten (2012) have argued (see also Hällsten \& Pfeffer, 2017) that parental wealth could be a factor encouraging children to make more ambitious educational choices in that it provides "insurance" against eventual failure. It can, though, be shown (Bukodi \& Goldthorpe, 2019, Figure 1.6) that in Britain a strong relationship exists between household financial wealth and class.

\section{REFERENCES}

Boalt, G. (1947). Skolutbildning och skolresultat för barn ur olika samhällsgrupper i Stockholm. P. A. Norstedt and Söner.

Boudon, R. (1974). Education, opportunity and social Inequality. Wiley.

Breen, R., \& Goldthorpe, J. H. (1997). Explaining educational differentials: Towards a formal rational action theory. Rationality and Society, 9, 275-305.

Breen, R., Karlson, K. B., \& Holm, A. (2018). A note on the reformulation of the KHB method. Sociological Methods and Research, 42, 165-191.

Breen, R., van de Werfhorst, H., \& Jaeger, M. M. (2014). Deciding under doubt: A theory of risk aversion, time discounting preferences, and educational decision-making. European Sociological Review, 30, 258-270.

Buis, M. (2013). The composition of family background: The influence of the economic and cultural resources of both parents on the offspring's educational attainment in the Netherlands between 1939 and 1991. European Sociological Review, 29, 593-602.

Bukodi, E., Bourne, M., \& Betthäuser, B. (2017). Wastage of talent? Social origins, cognitive ability and educational attainment in Britain. Advances in Life Course Research, 34, 34-42.

Bukodi, E., Erikson, R., \& Goldthorpe, J. H. (2014). The effects of social origins and cognitive ability on educational attainment: Evidence from Britain and Sweden. Acta Sociologica, 57, 293-310.

Bukodi, E., \& Goldthorpe, J. H. (2013). Decomposing 'social origins': The effects of parents' class, status and education on the educational attainment of their children. European Sociological Review, 29, 1024-1039.

Bukodi, E., \& Goldthorpe, J. H. (2019). Social mobility and education in Britain: Research, politics and policy. Cambridge University Press.

Chan, T.-W. (2010). Social status and cultural consumption. Cambridge University Press.

Chan, T.-W., \& Goldthorpe, J. H. (2004). Is there a status order in contemporary British society? Evidence from the occupational structure of friendship. European Sociological Review, 20, 383-401.

Chan, T.-W., \& Goldthorpe, J. H. (2007). Class and status: The conceptual distinction and its empirical relevance. American Sociological Review, 72, 512-532.

Chowdry, H., Crawford, C., Dearden, L., Goodman, A., \& Vignoles, A. (2013). Widening participation in higher education: Analysis using linked administrative data. Journal of the Royal Statistical Society, Series A, 176, 431-457. 
Contini, D., \& Scagni, A. (2013). Social-origin inequalities in educational careers in Italy. Performance or decision effects. In M. Jackson (Ed.), Determined to succeed? Performance versus choice in educational attainment. Stanford University Press.

Cox, D., \& Wermuth, N. (1992). A comment on the coefficient of determination for binary Responses. The American Statistician, 46, 1-4.

Crawford, C., Dearden, L., Micklewright, J., \& Vignoles, A. (2017). Family background and university success. Oxford University Press.

Department for Education. (2019). 16-19 performance table points scores for level 3 qualifications.

Erikson, R. (1984). Social class of men, women and families. Sociology, 18, 500-514.

Erikson, R. (2016). Is it enough to be bright? Parental background, cognitive ability and educational attainment. European Societies, 18, 117-135.

Erikson, R., Goldthorpe, J. H., Jackson, M., Yaish, M., \& Cox, D. (2005). On class differentials in educational attainment. Proceedings of the National Academy of Science, 102, 9730-9733.

Erikson, R., \& Jonsson, J. O. (1996). Explaining class inequality in educational attainment: The Swedish test case". In R. Erikson, \& J. O. Jonsson (Eds.), Can education be equalized?. Westview Press.

Erikson, R., \& Rudolphi, F. (2010). Change in social selection to upper secondary school: Primary and secondary effects in Sweden. European Sociological Review, 26, 291-305.

Erola, J., Jalonen, S., \& Lehti, H. (2016). Parental education, class and income over early life course and children's achievement. Research in Social Stratification and Mobility, 44, 33-43.

Gambetta, D. (1987). Were they pushed or did they jump? Individual decision mechanisms in education. Cambridge University Press.

Girard, A., \& Bastide, H. (1963). La stratification sociale et la démocratisation de l'enseignement. Population, 18, 435-472.

Goldthorpe, J. H. (1996/2000). Class analysis and the reorientation of class theory: The case of persisting differentials in educational attainment. The British Journal of Sociology, 47(3), 481.

Goldthorpe, J. H., \& McKnight, A. (2006). The economic basis of social class". In S. Morgan, D. B. Grusky, \& G. S. Fields (Eds.), Mobility and inequality: Frontiers of research from sociology and economics. Stanford University Press.

Hällsten, M., \& Pfeffer, F. T. (2017). Grand advantage: Family wealth and grandchildren's educational achievement in Sweden. American Sociological Review, 82, 328-360.

Hansen, K., \& Vignoles, A. (2005). The United Kingdom education system in a comparative context. In S. Machin, \& A. Vignoles (Eds.), What's the good of education? The economics of education in the UK. Princeton University Press.

Hobbs, G., \& Vignoles, A. (2010). Is children's free school meals eligibility a good proxy for family income? British Educational Research Journal, 36, 673-690.

Jackson, M. (2013a). Determined to succeed? Performance versus choice in educational attainment. Stanford University Press.

Jackson, M. (2013b). Introduction: How is inequality of educational opportunity generated? The case for primary and secondary effects. In M. Jackson (Ed.), Determined to succeed? Performance versus choice in educational attainment. Stanford University Press.

Jackson, M. (2013c). Social background and educational transitions in England. In M. Jackson (Ed.), Determined to succeed? Performance versus choice in educational attainment. Stanford University Press.

Jackson, M., Erikson, R., Goldthorpe, J. H., \& Yaish, M. (2007). Primary and secondary effects in class differentials in educational attainment: The transition to A-level courses in England and Wales. Acta Sociologica, 50, 211-229.

Jackson, M., \& Jonsson, J. O. (2013). Why does inequality of educational opportunity vary across countries? Primary and secondary effects in comparative context. In M. Jackson (Ed.), Determined to succeed? Performance versus choice in educational attainment. Stanford University Press.

Jaeger, M. M. (2007). Educational mobility across three generations: The changing impact of parental social class, economic, cultural and social capital. European Societies, 9, 527-550.

Kahneman, D. (2011). Thinking fast and slow. Allen Lane.

Kahneman, D., \& Tversky, A. (1979). Prospect theory: An analysis of decision under risk. Econometrica, 47, $263-291$.

Karlson, K. B., Holm, A., \& Breen, R. (2012). Comparing regression coefficients between same-sample nested models using logit and probit: A new method. Sociological Methodology, 42, 286-313.

Kartsonaki, C., Jackson, M., \& Cox, D. (2013). Primary and secondary effects: Some methodological issues. In M. Jackson (Ed.), Determined to succeed? Performance versus choice in educational attainment. Stanford University Press.

Kohler, U., Karlson, K. B., \& Holm, A. (2011). Computing coefficients for nested nonlinear probability models. The Stata Journal, 11, 420-438.

Kounali, D., Robinson, T., Goldstein, H., \& Lauder, H. (2008). The probity of Free School Meals as a Proxy Measure for Disadvantage. University of Bristol, Centre for Multilevel Modelling Research.

Lazarsfeld, P. (1939). "Interchangeability of indices in the measurement of economic influences. Journal of Applied Psychology, 23, 33-45. 
Murphy, R., Scott-Clayton, J., \& Wyness, G. (2019). The end of free college in England: Implications for enrolments, equity, and quality. Economics of Education Review, 71, 7-22.

Office for National Statistics. (2005). The National Statistics Socio-economic Classification: User manual. Palgrave Macmillan.

Ofqual. (2018). Grading new GCSEs.

Pfeffer, F. T. (2008). Persistent inequality in educational attainment and its institutional context. European Sociological Review, 24, 543-565.

Pfeffer, F. T., \& Hällsten, M. (2012). Mobility regimes and parental wealth: the United States, Germany and Sweden in comparative perspective. University of Michigan, Population Studies Centre.

Rees, A., \& Azzolini, D. (2014). Primary and secondary effects of social background on educational attainment in Italy: Evidence from an administrative dataset. Italian Journal of Sociology of Education, 6, 53-80.

Rudolphi, F. (2013). Ever-declining inequalities? Transitions to upper secondary and tertiary education in Sweden, 19721990 birth cohorts. In M. Jackson (Ed.), Determined to succeed? Performance versus choice in educational attainment. Stanford University Press.

Schütz, G., Ursprung, H., \& Woessmann, L. (2005). Education policy and equality of opportunity.

Strand, S. (2006). Comparing the predictive validity of reasoning tests and national end of Key Stage 2 tests: Which tests are the best? British Educational Research Journal, 32, 209-225.

Triventi, M. (2013). Stratification in higher education and its relationship with social inequality: A comparative study of 11 European nations. European Sociological Review, 29, 489-552.

Winship, C., \& Mare, R. (1984). Regression models with ordinal variables. American Sociological Review, 49, $512-525$.

Wolf, A., Jenkins, A., \& Vignoles, A. (2006). Certifying the workforce: Economic imperative or failed social policy? Journal of Education Policy, 21, 535-565.

Zhao, Y., \& Bukodi, E. (2020). Data Note: Measuring Social Origins and Educational Attainment in the Longitudinal Study of Young People in England (LSYPE), [Waves 1 - 8]. SocArXiv.

\section{SUPPORTING INFORMATION}

Additional Supporting Information may be found online in the Supporting Information section.

How to cite this article: Bukodi E, Goldthorpe JH, Zhao Y. Primary and secondary effects of social origins on educational attainment: New findings for England. Br J Sociol. 2021;72:627-650. https://doi. org/10.1111/1468-4446.12845 